\title{
Home food environment and associations with weight and diet among U.S. adults: a cross-sectional study
}

\author{
Michelle C. Kegler ${ }^{*}$ (D), April Hermstad and Regine Haardörfer
}

\begin{abstract}
Background: The home provides the physical and social context for the majority of eating behaviors for U.S. adults. This study describes eleven dimensions of the home food environment among a national sample of U.S. adults and identifies which are associated with diet quality and overweight/obesity.

Methods: A national sample of U.S. adults ages 18 to 75 was recruited from an online survey panel. Respondents ( $n=4942$ ) reported on foods available in the home, including 1$)$ fruit and vegetables, 2) salty snacks/sweets, 3) less healthy beverages, as well as 4) food placement, 5) shopping practices for fruits and vegetables, 6) food preparation, 7) portion control methods, 8) family meals from restaurants, 9) family household practices around TV and eating, 10) presence of a TV in the dining area, and 11) ownership of a scale. Self-reported height and weight, fruit and vegetable intake, and percent calories from fat were also assessed.

Results: Mean household size was 2.6, 32.7\% had children in the home, and $23.1 \%$ lived alone. The majority were White (67.7\%), with 12.3\% Black and 14.3\% Hispanic. Mean age was 44.4 and $48.3 \%$ were men. In multivariable models, seven features of the home food environment were associated with meeting the recommended fruit and vegetable intake guidelines, with food placement, meal preparation, frequency of shopping for fruit, and a greater variety of fruits and vegetables available in the home most strongly associated. Eight of 11 features were associated with percent energy from fat, including restaurant food for family meals, salty snacks and sweets availability, less healthy beverages availability, food placement, meal preparation, frequency of shopping for fruit, family eating with the TV on, and having a TV in the dining area. More diverse fruit and vegetable availability was associated with lower odds of overweight/obesity, and more frequent family eating while watching TV was associated with increased odds of overweight/obesity.
\end{abstract}

Conclusion: Targeting these dimensions of the home food environment may be a promising approach for future intervention research.

Keywords: Home environment, Obesity, Diet quality, Food inventory, Fruit and vegetable intake, Cross-sectional survey

\footnotetext{
* Correspondence: mkegler@emory.edu

Emory Prevention Research Center, Rollins School of Public Health, Emory

University, 1518 Clifton Road NE, Atlanta, GA 30322, USA
}

(C) The Author(s). 2021 Open Access This article is licensed under a Creative Commons Attribution 4.0 International License, which permits use, sharing, adaptation, distribution and reproduction in any medium or format, as long as you give appropriate credit to the original author(s) and the source, provide a link to the Creative Commons licence, and indicate if changes were made. The images or other third party material in this article are included in the article's Creative Commons licence, unless indicated otherwise in a credit line to the material. If material is not included in the article's Creative Commons licence and your intended use is not permitted by statutory regulation or exceeds the permitted use, you will need to obtain permission directly from the copyright holder. To view a copy of this licence, visit http://creativecommons.org/licenses/by/4.0/ The Creative Commons Public Domain Dedication waiver (http://creativecommons.org/publicdomain/zero/1.0/) applies to the data made available in this article, unless otherwise stated in a credit line to the data. 


\section{Background}

The majority of Americans do not meet the U.S. Dietary Guidelines, and identifying potential leverage points for improving diet continues as a public health priority [1]. Because a majority of food is still consumed at home, even with the proportion diminishing in the past few decades the home is a proximal environment to much of the eating behavior of Americans [2]. A number of studies have examined one or two aspects of the home environment, such as foods available in the home or frequency of shared family meals [3-9], but relatively few have examined a comprehensive set of home environment features and their possible association with weight and diet quality. Those that have, tend to focus on how home environments influence childhood obesity or diet [10-12]. Given the potentially powerful role that home environments play in shaping dietary behaviors, it is important to identify which dimensions are most influential as potential intervention targets.

Food inventories, or the foods available in the home, are the most commonly studied feature of the home food environment. Several studies have documented associations between home food inventories and a range of diet-related outcomes [5, 13-16]. While most of these studies have focused on children [3,12, 13, 17], some included parents $[14,18]$ and a few have focused on adults $[5,15,16,19]$. Placement of food within the home, or accessibility, is another potentially important dimension of the home food environment. Several studies have shown that accessibility of fruits and vegetables in the home is associated with fruit and vegetable intake in children [10, $12,13,20]$. Studies of home food accessibility are less common in adults, and report mixed findings [10, 19].

Quality of the food available in the home is dependent on food acquisition behaviors, such as grocery shopping and serving restaurant food for family meals. Grocery shopping behaviors have received a considerable amount of attention in the literature with increased attention on how the food environment influences dietary behavior [21-25], and shopping frequency is correlated with fruit and vegetable intake in several studies [21, 26, 27], but not with obesity in another [25]. Many studies that focus on the role of the home in childhood obesity examine parental practices related to food, such as eating meals in the living/TV area, taking second helpings, eating while watching TV [10], fast food and full servicerestaurant food for family meals [28], and food preparation $[29,30]$. These same practices are less commonly examined in adults.

At present, there is no consensus and limited research on which features of the home food environment are most influential for diet quality and weight-related behaviors of adults. As part of a weight gain prevention intervention, we developed a conceptual model for home food environments [31, 32] and examined its influence on fruit and vegetable intake and percent energy from fat in low-income overweight and obese women [19]. This model categorizes features of the home food environment into home food availability and cues (e.g., fruit and vegetable inventory, salty snacks/sweets inventory, unhealthy drinks, food placement), household food practices (e.g., food shopping, meal preparation non-home food sources, and household TV and eating), and social support and modeling. The current study extends our past work [19, 31, 32] by characterizing the home food environment of a national sample of U.S. adults and identifying associations with diet quality and overweight/ obesity.

\section{Methods}

\section{Study participants}

Participants $(n=4942)$ completed a cross-sectional survey during a two-week period in the fall of 2015. They were recruited from an internet panel using quota rather than probability-based sampling to match U.S. demographics on race/ethnicity, gender, age, income and geographic region. The panel, constructed and maintained by Lightspeed GMI (www.lightspeedresearch.com) is recruited from multiple sources (e.g., social media, banner ads, opt-in email, networks). We obtained completed surveys from (39.9\%) of 12,396 individuals who consented to participate. Those not satisfying enrollment quotas $(n=3811,30.7 \%)$, not completing the survey ( $n=2994,24.2 \%)$, and failing an in-survey quality control checks $(n=649,5.2 \%)$ were excluded. Study participants lived in the U.S., could read English, and were 18 to 75 years of age. The study protocol was approved by the Emory University Institutional Review Board.

\section{Measures}

Self-reported height and weight were used to calculate BMI, which was then dichotomized into underweight/normal $\left(\right.$ BMI $\left.<25 \mathrm{~kg} / \mathrm{m}^{2}\right)$ and overweight/obese $(\mathrm{BMI} \geq 25$ $\mathrm{kg} / \mathrm{m}^{2}$ ) for analyses [33]. Intake (frequency and amount) for nine categories of fruit or vegetables were used to calculate total cups of fruit and vegetables consumed per day using a validated measure [34] and then dichotomized based on the Dietary Guidelines for Americans 20152020 [35]. Those consuming 4.5 cups or more of fruit and vegetables per day were classified as meeting the guidelines. The validated National Cancer Institute Quick Food Scan was used to assess percent energy from fat [36].

We assessed eleven dimensions of the home food environment, three related to household food inventories. We asked about the availability of 16 fruits, 21 vegetables, 23 snacks and sweets, and eight beverages in the home during the past 7 days $[10,15,37,38]$. For fruits and vegetables, respondents were able to add additional 
fruits and vegetables in an open-ended field. For analyses reported here, we included three high fat/sugar beverages and eight high fat/sugar snacks/sweets. We also asked about frequency of purchasing fruits and vegetables in the past month, with response options of less than once per week, once per week, and more than once per week. Responses were dichotomized to less than once per week and one or more times per week [31].

Food placement measures consisted of three items that asked how often fruits, vegetables, and high calorie snack foods are kept in a place where they are easily seen and reached [10] using a 5-point scale from never to almost always. An overall food placement score was created by reverse coding the snack item and combining it with the fruit and vegetable placement items.

A total of 15 items were used to assess frequency of healthy and less healthy meal preparation, with a Cronbach's alpha of $.80[31,39]$. Items asked about food preparation methods (e.g., trim fat/skin from meat/chicken before cooking), specific cooking methods (e.g., use of a steamer, grill, added fats), and types of food served (e.g., fried foods, reduced fat/calorie milk, dressing, and frozen desserts, and fruits or vegetables). Portion control practices were assessed through three items (i.e., use of smaller plates, limiting portions, "family-style" meals) and combined to form an overall score. Response options were $1=$ never to $5=$ almost always. Overall scores were created for each, with items reverse coded as appropriate.

Family (or household) meals from restaurants was assessed by asking how often in a typical week family meals were obtained from fast-food restaurants, fullservice/sit-down restaurants, or takeout/delivery. For respondents who lived alone, items from a parallel question about their own meals from each of these sources was used [40]. An overall score was created by summing the days per week each type of restaurant was used, and then creating a daily average.

Using measures adapted from Spurrier and colleagues [11], all participants were asked two questions about how often they personally ate meals and snacks while watching $T V$. Participants who reported living with others answered two similar questions about household meals and snacks. The former was used for respondents who lived alone and the latter for those who had more than one person in the household. These questions used a five-point scale, with responses ranging from never to almost always. One question determined whether any televisions were in the room where main meals were eaten [11]. The final home environment measure asked whether they owned a scale for monitoring body weight.

\section{Demographics}

Respondents were also asked about their age, sex, race/ ethnicity, educational attainment, annual household income, marital status, household size and composition, employment status [33, 41], and to classify the area around their home as rural, small town, suburban, or urban.

\section{Data analysis}

All analyses were conducted using SAS (SAS version 9.4, SAS Institute Inc., Cary, NC., USA). Descriptive statistics were used to examine demographic, home food environment, BMI and diet-related variables. Independent $\mathrm{t}$ tests, Chi-square tests of independence, and Pearson correlations were used to explore bivariate relationships between features of the home food environment, overweight/obesity and dietary intake. Multivariable linear and logistic regression models were used to assess relationships between features of the home food environment and overweight/obesity (BMI $\geq 25$ ), meeting of fruit and vegetable guidelines, and percent calories from fat, adjusted for gender, age, race, income, and type of neighborhood.

\section{Results \\ Description of survey respondents}

Table 1 describes the survey respondents. The mean age was $44.4(\mathrm{SD}=15.4)$ and $48.3 \%$ were men. About onethird had children in the home (32.7\%) and $23.1 \%$ lived alone. Mean household size was $2.6(\mathrm{SD}=1.58)$. The majority were White $(67.7 \%)$, with $12.3 \%$ Black and $14.3 \%$ Hispanic. Approximately half $(50.1 \%)$ had college or graduate degrees, $30.7 \%$ reported some college or technical school, and 19.2\% reported a high school education or less. Close to one-third reported an annual household income over $\$ 75,000(32.5 \%)$ and $25.3 \%$ reported less than $\$ 25,000$. A normal BMI was reported most often (37.1\%) with $29.5 \%$ overweight and $30.2 \%$ obese. Only $17.9 \%$ consumed 4.5 cups of fruit and vegetables per day, and the mean percent calories from fat was 35.1 $(\mathrm{SD}=5.23)$.

\section{Description of the home food environment}

Table 2 presents a description of the home food environment, including the most commonly available fruits and vegetables. On average, respondents reported a mean of $5.2(\mathrm{SD}=3.65)$ different varieties of fruits in the home, with apples $(74.5 \%)$, bananas (72.2\%) and grapes (48.2\%) most common. Respondents reported 9.1 (SD = 4.79) varieties of vegetables in the home, with onions (71.1\%), carrots $(71.1 \%)$ and tomatoes (70.8\%) most common. Total varieties of fruits and vegetables in the home averaged $14.3(\mathrm{SD}=7.71)$ across respondents. Of the eight salty snacks and sweets assessed, an average of $3.8(\mathrm{SD}=2.08)$ kinds were available in the home; $69.9 \%$ of households had chocolate/candy/candy bars and 62.1\% had cookies/cakes/snack cakes/donuts. Potato 
Table 1 Description of Survey Respondents $(n=4942)$

\begin{tabular}{|c|c|c|}
\hline \multicolumn{3}{|l|}{ Characteristic } \\
\hline Age, mean, SD & 44.4 & 15.4 \\
\hline Sex, $n, \%$ male & 2389 & $48.3 \%$ \\
\hline Children $<18$ in the home, $n, \%$ & 1617 & $32.7 \%$ \\
\hline Live Alone, $n, \%$ & 1142 & $23.1 \%$ \\
\hline Household size, mean, SD & 2.6 & 1.58 \\
\hline \multicolumn{3}{|l|}{ Race/ethnicity, n, \% } \\
\hline White & 3335 & $67.7 \%$ \\
\hline Black & 604 & $12.3 \%$ \\
\hline Hispanic & 703 & $14.3 \%$ \\
\hline Asian & 254 & $5.2 \%$ \\
\hline Other & 29 & $0.6 \%$ \\
\hline \multicolumn{3}{|l|}{ Education, $n, \%$} \\
\hline HS diploma, GED, or less & 949 & $19.2 \%$ \\
\hline Some College or Technical School & 1519 & $30.7 \%$ \\
\hline College Degree or More & 2474 & $50.1 \%$ \\
\hline Employed, n, \% & 2786 & $56.4 \%$ \\
\hline \multicolumn{3}{|l|}{ Annual Household Income, n, \% } \\
\hline$<\$ 25,000$ & 1251 & $25.3 \%$ \\
\hline$\$ 25,000$ to $\$ 49,999$ & 1191 & $24.1 \%$ \\
\hline$\$ 50,000$ to $\$ 74,999$ & 893 & $18.1 \%$ \\
\hline$\$ 75,000+$ & 1607 & $32.5 \%$ \\
\hline \multicolumn{3}{|l|}{ BMI, $n^{*}, \%$} \\
\hline $15-18.4$ & 155 & $3.3 \%$ \\
\hline 18.5 to $<25$ & 1763 & $37.1 \%$ \\
\hline 25 to 29.9 & 1402 & $29.5 \%$ \\
\hline$\geq 30$ & 1435 & $30.2 \%$ \\
\hline \multicolumn{3}{|l|}{ Fruit and Vegetable Intake, $n, \%$} \\
\hline $\begin{array}{l}\text { Meet fruit and vegetable intake guidelines } \\
(4.5 \text { cups/day) }\end{array}$ & 886 & $17.9 \%$ \\
\hline$\%$ calories from fat ${ }^{*}$, mean, SD & 35.1 & 5.23 \\
\hline
\end{tabular}

$\mathrm{N}$ for $\mathrm{BMI}=4755$ (187 missing), $\mathrm{N}$ for Percent calories from fat $=4938$ (4 missing)

chips were available in $61.5 \%$ of households. Of the three high-fat/high-sugar beverages assessed, households had a mean of 1.5 kinds $(\mathrm{SD}=1.02)$ available in the home. Over half $(61.5 \%)$ of households reported whole milk $(61.5 \%)$ and regular soft drinks (55.4\%). The mean food placement score was $2.5(\mathrm{SD}=0.69)$, meaning that unhealthy foods were between sometimes and frequently kept out of sight and easy reach, and fruits and vegetables were easy to see and reach.

The majority of respondents reported shopping for both fruits and vegetables at least once a week, 78.8\% for fruit and $76.4 \%$ for vegetables. The mean meal preparation score was $1.9(\mathrm{SD}=0.66)$ which corresponds with sometimes. The most common healthy food preparation behaviors were related to meat purchasing or preparation and using a non-stick pan with no grease. Serving a range of low fat food was less common (e.g., lowcalorie salad dressing, low-fat mayonnaise). The portion control score was also $1.9(\mathrm{SD}=0.73)$, with little differentiation across specific practices.

Various types of restaurants, including fast food, sitdown and take out/delivery, were used for family/household meals a mean of 0.7 times per day $(\mathrm{SD}=0.78)$. Family meals and snacks with the TV on occurred between sometimes and frequently on average, with $25.3 \%$ percent stating their household almost always ate meals in front of the TV and $23.3 \%$ stated their household almost always ate snacks in front of the TV.

The majority owned a scale (75.8\%) and had a TV in the room where main meals were eaten (61.5\%).

Bivariate associations between features of the home food environment, diet quality, and obesity/overweight

All features of the home food environment were significantly associated with meeting national fruit and vegetable guidelines in bivariate analyses (Table 3), including diversity of the fruit and vegetable inventory (20.6 for met versus 13.0 for unmet), food placement ( 2.7 for met versus 2.4 for unmet), shopping for fruit at least once per week (90.9\% versus $76.2 \%)$, meal preparation (2.3 versus 1.8), portion control (2.1 versus 1.9$)$, and owning a scale $(81.4 \%$ versus $74.5 \%)$. Salty snacks/sweets ( 4.5 for met versus 3.6 for unmet), unhealthy beverages (1.8 for met versus 1.1 for unmet), family eating in front of the TV (2.6 versus 2.4$)$, a TV in the dining area $(70.5 \%$ versus $59.6 \%$ ), and family meals from restaurants (1.2 versus 0.6) were also associated with meeting of guidelines.

Nine of the home food environment features were associated with percent calories from fat, although correlations were generally modest as shown in Table 3 . The highest correlations were for family meals from restaurants $(r=.41)$, salty snacks/sweets $(r=.25)$, unhealthy beverages $(r=.24)$, and eating with the TV on $(r=.18)$. Meal preparation, portion control were significant, but not meaningfully correlated. Food placement was negatively correlated $(r=-.14)$, fruit and vegetable inventory was positively associated with percent calories from fat $(r=.15)$. Shopping frequency for fruit was associated with fat intake, but the difference was too small to be meaningful. TV in the dining area and owning a scale were not associated with percent calories from fat.

Fewer features of the home food environment were associated with overweight/obesity, with salty snacks/ sweets inventory, less healthy beverages inventory, portion control practices, and owning a scale not related. Features associated with overweight/obesity included fruit and vegetable inventory (14.9 for under/normal weight versus 13.5 for overweight/obese), shopping for 
Table 2 Household Food Inventory and Household Food Practices $(n=4942)$

\begin{tabular}{|c|c|c|}
\hline Feature & $\begin{array}{l}\mathrm{N} \text { or } \\
\text { Mean }\end{array}$ & $\begin{array}{l}\text { Percen } \\
\text { or SD }\end{array}$ \\
\hline Total varieties of fruit (of 17), mean, (SD) & 5.2 & $(3.65)$ \\
\hline \multicolumn{3}{|l|}{ Top 5, n, \% } \\
\hline Apples & 3684 & 74.5 \\
\hline Bananas & 3569 & 72.2 \\
\hline Grapes & 2382 & 48.2 \\
\hline Oranges & 2230 & 45.1 \\
\hline Strawberries & 1945 & 39.4 \\
\hline Total varieties of vegetables (of 22), mean, (SD) & 9.1 & $(4.79)$ \\
\hline \multicolumn{3}{|l|}{ Top 5, n, \% } \\
\hline Onions & 3515 & 71.1 \\
\hline Carrots & 3514 & 71.1 \\
\hline Tomatoes & 3498 & 70.8 \\
\hline Lettuce & 3407 & 68.9 \\
\hline Broccoli & 3159 & 63.9 \\
\hline Total fruit and vegetables (of 39), mean, (SD) & 14.3 & $(7.71)$ \\
\hline Total salty snacks/sweets (of 8), mean, (SD) & 3.8 & $(2.08)$ \\
\hline \multicolumn{3}{|l|}{ Top 5, n, \% } \\
\hline Chocolate/candy/candy bars & 3455 & 69.9 \\
\hline Cookies/cakes/snack cakes/donuts & 3071 & 62.1 \\
\hline Potato chips & 3038 & 61.5 \\
\hline Ice cream & 2615 & 52.9 \\
\hline Snack crackers & 2381 & 48.2 \\
\hline Total less healthy beverages (of 3), mean, (SD) & 1.5 & $(1.02)$ \\
\hline Whole milk & 3038 & 61.5 \\
\hline Regular soft drinks & 2737 & 55.4 \\
\hline Sugar-sweetened beverages, non-soda & 1871 & 37.9 \\
\hline Food placement scale (of 3), mean, (SD) & 2.5 & $(0.69)$ \\
\hline Fruits, \% almost always (easy to see/reach) & 2146 & 43.4 \\
\hline Vegetables, $\%$ almost always & 1570 & 31.8 \\
\hline Unhealthy snacks, \% almost always ${ }^{\mathrm{b}}$ & 1261 & 25.5 \\
\hline \multicolumn{3}{|l|}{ Grocery shopping $\geq 1 /$ week } \\
\hline For fruit, n, \% & 3895 & 78.8 \\
\hline For vegetables, n, \% & 3773 & 76.4 \\
\hline Meal preparation scale ${ }^{a}$, mean, (SD) & 1.9 & $(0.66)$ \\
\hline Buy skinless chicken or remove skin & 2.3 & $(1.37)$ \\
\hline Buy lean meat or trim fat & 2.2 & $(1.32)$ \\
\hline Use a non-stick pan and no grease & 2.2 & $(1.22)$ \\
\hline Serve fruit or vegetables for snacks & 2.1 & $(1.15)$ \\
\hline Use spices on vegetables instead of oil, butter or fat & 2.1 & $(1.27)$ \\
\hline Broil or bake meat or fish & 2.0 & $(1.24)$ \\
\hline Serve fruit for dessert & 1.9 & $(1.22)$ \\
\hline Cook with a grill & 1.6 & $(1.21)$ \\
\hline Serve $1 \%$ or skim milk & 1.6 & $(1.53)$ \\
\hline
\end{tabular}

Table 2 Household Food Inventory and Household Food Practices $(n=4942)$ (Continued)

\begin{tabular}{|c|c|c|}
\hline Feature & $\begin{array}{l}\mathrm{N} \text { or } \\
\text { Mean }\end{array}$ & $\begin{array}{l}\text { Percent } \\
\text { or SD }\end{array}$ \\
\hline Use low calorie or diet salad dressings & 1.4 & $(1.34)$ \\
\hline Use low-fat or non-fat mayonnaise & 1.2 & $(1.34)$ \\
\hline Serve non-fat ice cream, frozen yogurt or sherbet & 1.1 & $(1.24)$ \\
\hline Cook with a steamer & 1.1 & $(1.22)$ \\
\hline Serve fried fish or fried chicken ${ }^{b}$ & 1.4 & (1.18) \\
\hline Serve fried vegetables like okra or $\mathrm{FF}^{\mathrm{b}}$ & 1.2 & $(1.17)$ \\
\hline Portion control score ${ }^{a}$, mean, (SD) & 1.9 & $(0.73)$ \\
\hline Use smaller plates & 1.7 & $(1.24)$ \\
\hline Serve smaller amounts of food & 1.7 & $(1.15)$ \\
\hline Serve meals family style ${ }^{b}$ & 1.7 & $(1.33)$ \\
\hline $\begin{array}{l}\text { Restaurant food for family meals, times/day, } \\
\text { mean, SD }\end{array}$ & 0.7 & $(0.78)$ \\
\hline Family TV and eating ${ }^{a}$, mean, (SD) & 2.5 & $(1.13)$ \\
\hline Meals, n, \% almost always & 1251 & 25.3 \\
\hline Snacks, $n, \%$ almost always & 1153 & 23.3 \\
\hline Own scale, $n, \%$ yes & 3744 & 75.8 \\
\hline TV in dining area, $\mathbf{n}, \%$ yes & 3041 & 61.5 \\
\hline
\end{tabular}

fruit (81.4\% versus $77.0 \%$ ), meal preparation (1.9 versus $1.8)$, watching TV while eating (2.3 versus 2.5$)$, TV in the dining area $(59.1 \%$ versus $62.0 \%)$, and household meals from restaurant food (0.73 for under/normal weight versus 0.65 for overweight/obese). The association with food placement was also significant but too small to be meaningful.

\section{Multivariable analyses}

Table 4 presents regression models that examine which dimensions of the home food environment were associated with meeting national guidelines for fruit and vegetable intake, percent calories from fat, and overweight/ obesity. While controlling for demographic variables and type of neighborhood based on level of rurality, seven of 11 features of the home food environment were associated with meeting fruit and vegetable intake guidelines. The strongest associations were restaurant food for household meals $(\mathrm{OR}=1.73$; $\mathrm{CI} 1.54,1.94)$, food placement $(\mathrm{OR}=1.49$, CI $1.28,1.74)$, meal preparation $(\mathrm{OR}=$ $1.48, \mathrm{CI} 1.25,1.76)$, and frequency of shopping for fruit $(\mathrm{OR}=1.52$, CI 1.14, 2.01). Having more types of fruit and vegetables in the home $(\mathrm{OR}=1.09, \mathrm{CI} 1.08,1.11)$ was also associated with meeting the guidelines, as were having a TV in the dining area $(\mathrm{OR}=1.36, \mathrm{CI} 1.11$, 1.67), and having more salty/sweet snacks in the home $(\mathrm{OR}=1.06,1.01,1.12)$. 


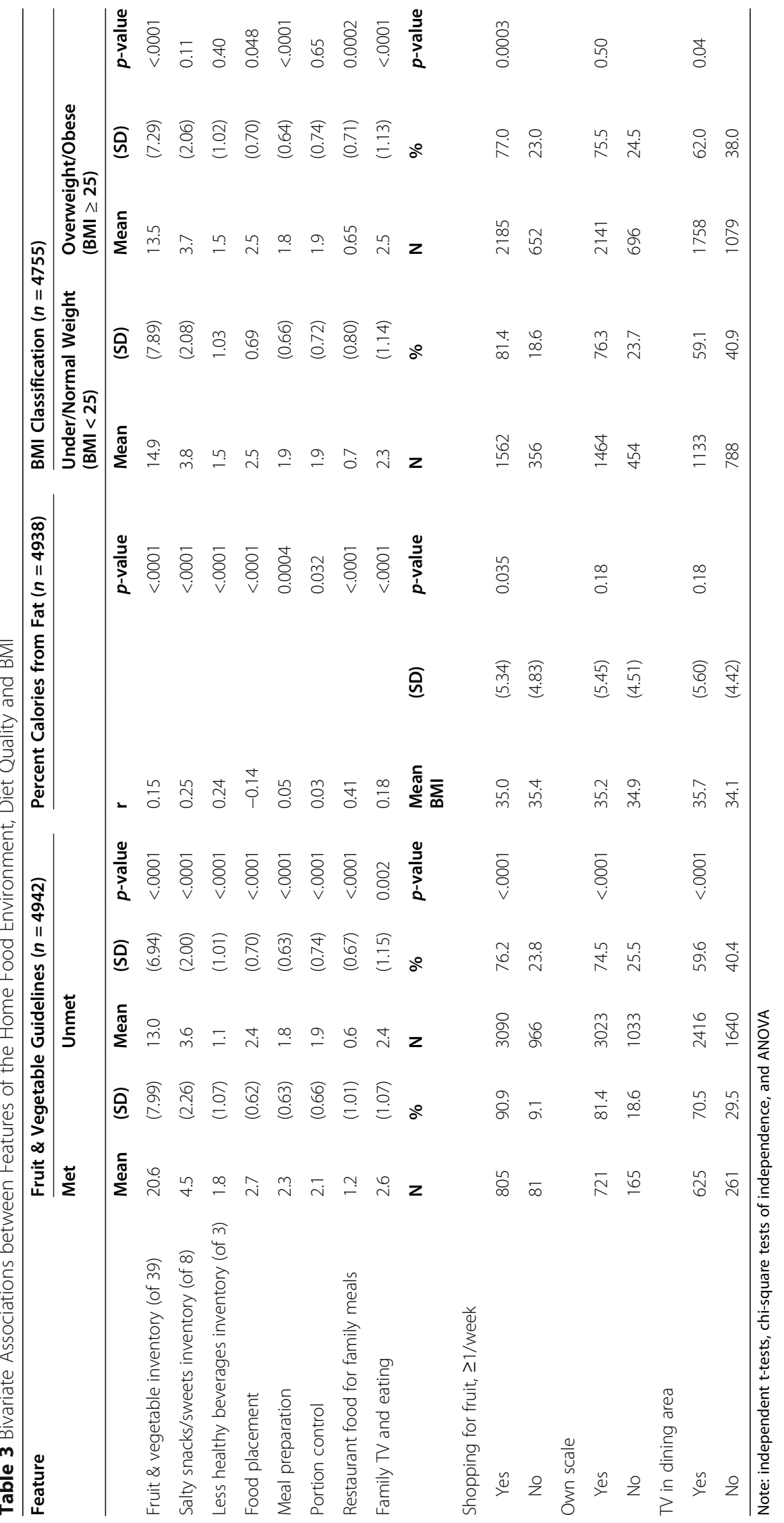


Table 4 Regression Models for Home Food Environments, Dietary Intake and Overweight/Obesity

\begin{tabular}{|c|c|c|c|c|c|c|c|}
\hline \multirow[t]{2}{*}{$\begin{array}{l}\text { Feature of the Home Food } \\
\text { Environment }\end{array}$} & \multicolumn{2}{|c|}{$\begin{array}{l}\text { Logistic Regression Model } \\
\text { Met Fruit \& Vegetable Guidelines } \\
(n=4921)\end{array}$} & \multicolumn{3}{|c|}{$\begin{array}{l}\text { Multiple Regression Model for } \\
\text { Percent Calories from Fat } \\
(n=4917)\end{array}$} & \multicolumn{2}{|c|}{$\begin{array}{l}\text { Logistic Regression Model for } \\
\text { Overweight/Obesity }(n=4735)\end{array}$} \\
\hline & OR & $(95 \% \mathrm{Cl})$ & b & SE & $p$-value & OR & $(95 \% \mathrm{Cl})$ \\
\hline Fruit \& vegetable inventory & 1.09 & $(1.08,1.11)$ & 0.06 & 0.01 & $<.0001$ & 0.98 & $(0.97,0.99)$ \\
\hline Salty snacks/sweets inventory & 1.06 & $(1.01,1.12)$ & 0.23 & 0.04 & $<.0001$ & 1.00 & $(0.97,1.04)$ \\
\hline Less healthy beverages inventory & 0.95 & $(0.86,1.04)$ & 0.51 & 0.07 & $<.0001$ & 1.04 & $(0.97,1.12)$ \\
\hline Food placement & 1.49 & $(1.28,1.74)$ & -0.37 & 0.11 & 0.0008 & 1.04 & $(0.94,1.15)$ \\
\hline Meal preparation & 1.48 & $(1.25,1.76)$ & -0.45 & 0.13 & 0.0006 & 1.02 & $(0.90,1.16)$ \\
\hline Portion control & 1.04 & $(0.91,1.18)$ & 0.08 & 0.10 & 0.4024 & 1.03 & $(0.94,1.13)$ \\
\hline Restaurant food for family meals & 1.73 & $(1.54,1.94)$ & 2.17 & 0.10 & $<.0001$ & 0.97 & $(0.88,1.06)$ \\
\hline Family TV and eating & 0.97 & $(0.89,1.06)$ & 0.32 & 0.07 & $<.0001$ & 1.14 & $(1.07,1.21)$ \\
\hline Grocery shopping for fruit & 1.52 & $(1.14,2.01)$ & -0.50 & 0.18 & 0.0047 & 0.95 & $(0.80,1.13)$ \\
\hline Own scale & 1.04 & $(0.84,1.29)$ & -0.01 & 0.16 & 0.9327 & 0.98 & $(0.84,1.13)$ \\
\hline TV in dining area & 1.36 & $(1.11,1.67)$ & 0.29 & 0.15 & 0.0601 & 0.99 & $(0.86,1.14)$ \\
\hline
\end{tabular}

All models controlled for gender, race, age, income and neighborhood rurality/urbanicity

Eight of 11 features of the home food environment were associated with percent energy from fat in the multivariable analysis. The strongest association was between restaurant food for household meals (i.e., fast food, sit down restaurants, or take-out/delivery) and percent calories from fat $(\mathrm{b}=2.17, \mathrm{SE}=0.10, p<.0001)$. Other associations were salty snacks and sweets $(\mathrm{b}=$ $0.23, \mathrm{SE}=0.04, p<.0001)$, unhealthy beverages $(\mathrm{b}=0.51$, $\mathrm{SE}=0.07, p<.0001)$, food placement $(\mathrm{b}=-0.37, \mathrm{SE}=$ $0.11, p=0.0008)$, meal preparation $(b=-0.45, \mathrm{SE}=0.13$, $p=0.0006)$, family eating with the TV on $(\mathrm{b}=0.32, \mathrm{SE}=$ $0.07, p<.0001)$, and frequency of shopping for fruit $(\mathrm{b}=$ $-0.50, \mathrm{SE}=0.18, p=0.005)$. Fruit and vegetable inventory was also associated with percent calories from fat $(\mathrm{b}=0.06, \mathrm{SE}=0.01, p<.0001)$, while portion control, having a TV in the dining room, and owning a scale were not.

Just two of the home food environment features were associated directly with overweight/obesity and these associations were small. More frequent household meals and snacks while watching TV was associated with increased odds of overweight/obesity $(\mathrm{OR}=1.14$, CI 1.07, 1.21 ), and an increased fruit and vegetable inventory was associated with lower odds of overweight/obesity (OR = 0.98, CI 0.97, 0.99).

\section{Discussion}

This paper characterizes multiple dimensions of the home food environments of U. S adults using a national sample. Prior research on home food environments generally examines sub-populations, often using baseline data from intervention trials, families with children, or a limited set of home food environment features. To our knowledge, this is the first study to examine multiple features of the home food environment using a national sample. Other national studies have used NHANES data to examine one or two dimensions [6, 42, 43]. Using NHANES data from 2007 to 2010, for example, Chai et al. [6] found that $85.4 \%$ of adults had fruits available in their home always or most of the time. Our study also showed relatively high fruit availability, with over $70 \%$ of households reporting apples and/or bananas in the home during the past 7 days. Chai et al. reported that $62.5 \%$ reported salty snacks, this is comparable to our finding that over $60 \%$ of households had regular potato chips in their homes. Additionally, Chai reported that $56.3 \%$ had sugary drinks available in the home all or most of the time. We found that over $50 \%$ had regular soft drinks in their home and over 35\% had non-soda sugar sweetened beverages.

It is more difficult to compare findings on other dimensions of the home food environment across studies given measurement differences and a focus on specific demographic groups or just one or two geographic areas $[4,7,10,18,44]$. Because we used many measures from our earlier study of home food environments among overweight and obese women in rural Georgia [19, 31], we can make some comparisons. In that study, there was an average of 14.0 varieties of fruits and vegetables available in the home compared to 14.3 in the current study. Other findings were also similar, with the exception of a higher portion control (called meal serving in the earlier study) score in the study of overweight/obese women than in the current study. This may be due to actual behavioral differences related to weight management strategies or social desirability.

To our knowledge, the current study is also the first to explore associations of multiple dimensions of the home 
food environment with important public health outcomes, including fruit and vegetable intake, percent calories from fat, and overweight/obesity in a national sample. We examined eleven dimensions of the home food environment and found that a majority were related to diet quality (e.g., meeting of fruit and vegetable guidelines and percent calories from fat) and two were associated with overweight and obesity in multivariable models. Taken together, the relationships observed in this study begin to show a pattern that may be instructive for future interventions. Fewer home food environment variables were associated with overweight/obesity in either bivariate or multivariate analyses, perhaps reflecting the complex relationship between weight, food, and myriad other factors, plus the more proximal nature of diet quality relative to weight.

Our finding that the varieties of fruits and vegetables present in the home was associated with an increased likelihood of meeting national fruit and vegetable guidelines is consistent with earlier studies, many of which have shown associations between fruit and vegetable inventory and fruit and vegetable intake in children $[13,14,17]$ and also adults [45]. Consistent with at least one other study [44], we also found that fruit and vegetable inventory was associated with a decreased likelihood of overweight/obesity. Surprisingly, we found that fruit and vegetable inventory was associated with increased percent energy from fat.

Other components of the home food inventory were also associated with dietary behavior. Both salty snacks and sweets, and unhealthy beverage inventories, were associated with higher levels of percent calories from fat. Somewhat surprisingly, a higher inventory of salty snacks and sweets was associated with increased likelihood of meeting fruit and vegetable intake guidelines. Few other studies have documented the constellation of snacks in the home and dietary outcomes. Among those that have, positive associations were noted between home availability of high fat snacks with fat intake $[5,15]$ and overweight [44].

We found that food placement was associated with decreased percent calories from fat and increased likelihood of meeting national fruit and vegetable guidelines. In our earlier study on overweight and obese women, we did not find any associations between food placement and fruit and vegetable intake or percent calories from fat [19]. Several studies had documented that increased accessibility was associated with fruit and vegetable intake in children $[10,12,13,20]$.

We also found that healthier meal preparation was associated with both increased likelihood of meeting fruit and vegetable intake guidelines and lower percent energy from fat. While few studies have examined meal preparation as a dimension of home food environments, several studies have examined whether food preparation methods are associated with diet and weight, yielding mixed results [19, 29, 30]. Trude et al. [30] reported that household food preparation was not associated with fruit and vegetable intake among adolescents, unless the adolescents were directly involved in the preparation. A study by Kramer and colleagues reported lower BMI among African American youth whose households used healthier food preparation methods [29]. Our earlier study found that healthy food preparation was associated with lower percent calories from fat [19].

Our portion control measure was not associated with any of the outcomes we examined in multivariable analyses. Despite studies that document how environmental factors such as plate size can influence amount of food consumed in laboratory settings $[46,47]$, to our knowledge, very few studies have examined whether behaviors to limit family portion sizes are associated with dietary behaviors or weight.

Shopping for fruit was associated with fruit and vegetable intake. Frequency of shopping has been shown to be associated with fruit and vegetable intake in a couple of studies $[19,21,26]$. We found that increased frequency of restaurant food for family meals was associated with increased percent energy from fat, and surprisingly, increased meeting of fruit and vegetable consumption, even when controlling for income. Boutelle et al. found that purchase of fast food for family meals was associated with lower vegetable intake and higher BMI among parents of adolescents [28]. Frequency of restaurant eating in general (i.e., not limited to family meals) has been examined in a larger number of studies, with findings that show frequency of away from home meals (i.e., fast food and fullservice restaurant food and beverage consumption) is associated with increased energy intake and BMI $[48,49]$.

Family meals and snacks with the TV on were associated with both percent intake from fat and overweight/ obesity in our study. Past studies have shown that frequency of TV on during dinner was associated with lower F \& V consumption in adults [50]; and that TV watching while eating was associated with percent energy from fat [51]. A TV in the dining room, however, was associated only with fruit and vegetable guidelines being met in our study. Other studies have shown that TV watching is associated with obesity [52]. Gorin found that more TVs in the household were associated with overweight and obesity [44]. Lastly, owning a scale was not associated with overweight/obesity or either of the diet quality outcomes in our study.

This study has a few important limitations. First, because the data are from an online sample, those without internet services are likely under-represented, as are those without a college degree. Although the sample was designed to match the U. S population on a few key characteristics, it is not probability-based, therefore inferences 
cannot be made to the full population. Second, the data are self-reported, and thus, susceptible to social desirability bias. Third, the data are from 2015 and do not reflect the possibly major changes made to home food environments as a result of the COVID-19 pandemic. We acknowledge that the home food environment is situated within a larger community food environment and that additional research is needed on the ways in which the home environment may mediate the association between the larger food environment and dietary outcomes. Nevertheless, this study makes an important contribution by providing one of the most comprehensive examinations of the home food environment published to date.

\section{Conclusion}

In this cross-sectional study, numerous dimensions of the home food environment, including food and beverage inventories, food placement, meal preparation, frequency of shopping, use of restaurant meals, and TV and eating practices, were associated with diet quality. A more diverse fruit and vegetable inventory was associated with lower odds of overweight/obesity, and more frequent family eating while watching TV was associated with increased odds of overweight/obesity. These findings have implications for how to improve diet quality. Although more intervention research is needed, targeting dimensions of the home identified in this study with motivational interviewing, goal setting or social marketing strategies may be a promising approach consistent with our understanding that environments can constrain and encourage health behaviors, including healthy eating. Changing the larger food environment in which home environments are situated may be an important complementary strategy. A deeper understanding of which dimensions can drive improvements in diet quality and healthy weight maintenance may strengthen current approaches to nutrition and obesity interventions.

\section{Abbreviations}

BMl: Body mass index; OR: Odds ratio

\section{Acknowledgements}

None.

\section{Authors' contributions}

MK led the study, drafted most of the paper and analyzed the data. $\mathrm{AH}$ contributed to study design, coordinated data collection, and drafted parts of the methods section. RH gave input into the study design and implementation. All authors reviewed and approved the final manuscript.

\section{Funding}

This research was supported with institutional funds from the Rollins School of Public Health, Emory University. The funder had no role in study design, data collection, analysis, interpretation of findings or in writing this manuscript.

\section{Availability of data and materials}

The dataset for the current study is available from the corresponding author on reasonable request.

\section{Declarations}

Ethics approval and consent to participate

This study was approved by the Emory University Institutional Review Board \#(IRB00083526) and all participants gave written informed consent.

\section{Consent for publication}

Not applicable.

\section{Competing interests}

The authors declare that they have no competing interests" in this section.

Received: 10 October 2020 Accepted: 19 May 2021

Published online: 01 June 2021

\section{References}

1. United States Department of Agriculture. Dietary Guidelines for Americans 2020-2025. Washington DC: United States Department of Agriculture. Available from: https://www.dietaryguidelines.gov. Accessed 15 Mar 2021.

2. Lin B-H, Guthrie J. Nutritional quality of food prepared at home and away from home, 1977-2008. Washington D.C: U.S. Department of Agriculture, Economic Research Service; 2012

3. Bruening M, McClain D, Moramarco M, Reifsnider E. The role of SNAP in home food availability and dietary intake among WIC participants facing unstable housing. Public Health Nurs. 2017;34(3):219-28. https:/doi.org/10.1111/phn.12311.

4. Quick V, Martin-Biggers J, Povis GA, Hongu N, Worobey J, Byrd-Bredbenner C. A socio-ecological examination of weight-related characteristics of the home environment and lifestyles of households with young children. Nutrients. 2017;9(6):604. https://doi.org/10.3390/nu9060604.

5. Grant E, Gearry R, Wilson R, Pearson J, Skidmore P. Home availability of fruit and vegetables and obesogenic foods as an indicator of nutrient intake in 50 year olds from Canterbury, New Zealand. Asia Pac J Clin Nutr. 2017;26(3): 524-30. https://doi.org/10.6133/apjcn.042016.11.

6. Chai W, Fan JX, Wen M. Association of individual and neighborhood factors with home food availability: evidence from the National Health and nutrition examination survey. J Acad Nutr Diet. 2018;1 18(5):815-23. https:// doi.org/10.1016/j.jand.2017.11.009

7. Green SH, Glanz K. Development of the perceived nutrition environment measures survey. Am J Prev Med. 2015;49(1):50-61. https://doi.org/10.1016/ j.amepre.2015.02.004.

8. Fulkerson JA, Larson N, Horning M, Neumark-Sztainer D. A review of associations between family or shared meal frequency and dietary and weight status outcomes across the lifespan. J Nutr Educ Behav. 2014;46(1): 2-19. https://doi.org/10.1016/j.jneb.2013.07.012.

9. Hammons AJ, Fiese $\mathrm{BH}$. Is frequency of shared family meals related to the nutritional health of children and adolescents? Pediatrics. 2011;127(6): e1565-74. https://doi.org/10.1542/peds.2010-1440.

10. Gattshall ML, Shoup JA, Marshall JA, Crane LA, Estabrooks PA. Validation of a survey instrument to assess home environments for physical activity and healthy eating in overweight children. Int J Behav Nutr Phys Act. 2008:5(1):3. https://doi.org/10.1186/1479-5868-5-3.

11. Spurrier NJ, Magarey AA, Golley R, Curnow F, Sawyer MG. Relationships between the home environment and physical activity and dietary patterns of preschool children: a cross-sectional study. Int J Behav Nutr Phys Act. 2008;5(1):31. https://doi.org/10.1186/1479-5868-5-31.

12. Wyse R, Campbell E, Nathan N, Wolfenden L. Associations between characteristics of the home food environment and fruit and vegetable intake in preschool children: a cross-sectional study. BMC Public Health. 2011;11(1):938. https://doi.org/10.1186/1471-2458-11-938.

13. Callender C, Liu Y, Moore CE, Thompson D. The baseline characteristics of parents and African American girls in an online obesity prevention program: a feasibility study. Prev Med Rep. 2017;7:110-5. https://doi.org/10.1016/.jpmedr.2017.05.011.

14. Bryant M, Stevens J, Wang L, Tabak R, Borja J, Bentley ME. Relationship between home fruit and vegetable availability and infant and maternal dietary intake in African-American families: evidence from the exhaustive home food inventory. J Am Diet Assoc. 2011;111(10):1491-7. https://doi. org/10.1016/j.jada.2011.07.007.

15. Patterson RE, Kristal AR, Shannon J, Hunt JR, White E. Using a brief household food inventory as an environmental indicator of individual dietary practices. Am J Public Health. 1997;87(2):272-5. https://doi.org/10.2105/AJPH.87.2.272. 
16. Hermstad AK, Swan DW, Kegler MC, Barnette JK, Glanz K. Individual and environmental correlates of dietary fat intake in rural communities: a structural equation model analysis. Soc Sci Med. 2010;71(1):93-101. https:// doi.org/10.1016/j.socscimed.2010.03.028.

17. Ding D, Sallis JF, Norman GJ, Saelens BE, Harris SK, Kerr J, et al. Community food environment, home food environment, and fruit and vegetable intake of children and adolescents. J Nutr Educ Behav. 2012;44(6):634-8. https:// doi.org/10.1016/j.jneb.2010.07.003.

18. Flórez KR, Richardson AS, Ghosh-Dastidar MB, Beckman R, Huang C, Wagner $L$, et al. Improved parental dietary quality is associated with children's dietary intake through the home environment. Obes Sci Pract. 2017;3(1):7582. https://doi.org/10.1002/osp4.81.

19. Kegler MC, Alcantara I, Haardorfer R, Gazmararian JA, Ballard D, Sabbs D. The influence of home food environments on eating behaviors of overweight and obese women. J Nutr Educ Behav. 2014;46(3):188-96. https://doi.org/1 0.1016/j.jneb.2014.01.001.

20. Wyse R, Campbell KJ, Brennan L, Wolfenden L. A cluster randomised controlled trial of a telephone-based intervention targeting the home food environment of preschoolers (the healthy habits trial): the effect on parent fruit and vegetable consumption. Int J Behav Nutr Phys Act. 2014;11(1):144. https://doi.org/10.1186/s12966-014-0144-6.

21. Liese AD, Ma X, Hutto B, Sharpe PA, Bell BA, Wilcox S. Food shopping and acquisition behaviors in relation to $\mathrm{BMl}$ among residents of low-income communities in South Carolina. Int J Environ Res Public Health. 2017;14(9): 1075. https://doi.org/10.3390/ijerph14091075.

22. LeDoux TF, Vojnovic I. Going outside the neighborhood: the shopping patterns and adaptations of disadvantaged consumers living in the lower eastside neighborhoods of Detroit, Michigan. Health Place. 2013;19:1-14. https://doi.org/10.1016/j.healthplace.2012.09.010.

23. Aggarwal A, Cook AJ, Jiao J, Seguin RA, Vernez Moudon A, Hurvitz PM, et al. Access to supermarkets and fruit and vegetable consumption. Am J Public Health. 2014;104(5):917-23. https://doi.org/10.2105/AJPH.2013.301763.

24. Drewnowski A, Aggarwal A, Hurvitz PM, Monsivais P, Moudon AV. Obesity and supermarket access: proximity or price? Am J Public Health. 2012;102(8): e74-80. https://doi.org/10.2105/AJPH.2012.300660.

25. Dubowitz T, Zenk SN, Ghosh-Dastidar B, Cohen DA, Beckman R, Hunter G, et al. Healthy food access for urban food desert residents: examination of the food environment, food purchasing practices, diet and BMI. Public Health Nutr. 2015;18(12):2220-30. https://doi.org/10.1017/S1368980014002742.

26. Liese AD, Bell BA, Barnes TL, Colabianchi N, Hibbert JD, Blake CE, et al. Environmental influences on fruit and vegetable intake: results from a path analytic model. Public Health Nutr. 2014;17(11):2595-604. https://doi.org/1 $0.1017 / S 1368980013002930$.

27. Larson N, Laska MN, Story M, Neumark-Sztainer D. Predictors of fruit and vegetable intake in young adulthood. J Acad Nutr Diet. 2012;112(8):121622. https://doi.org/10.1016/j.jand.2012.03.035.

28. Boutelle KN, Fulkerson JA, Neumark-Sztainer D, Story M, French SA. Fast food for family meals: relationships with parent and adolescent food intake, home food availability and weight status. Public Health Nutr. 2007;10(1):1623. https://doi.org/10.1017/S136898000721794X.

29. Kramer RF, Coutinho AJ, Vaeth E, Christiansen K, Suratkar S, Gittelsohn J. Healthier home food preparation methods and youth and caregiver psychosocial factors are associated with lower BMl in African American youth. J Nutr. 2012;142(5):948-54. https://doi.org/10.3945/jn.111.156380.

30. Trude AC, Kharmats AY, Hurley KM, Anderson Steeves E, Talegawkar SA, Gittelsohn J. Household, psychosocial, and individual-level factors associated with fruit, vegetable, and fiber intake among low-income urban African American youth. BMC Public Health. 2016;16(1):872. https://doi.org/10.1186/s12889-016-3499-6.

31. Kegler MC, Alcantara I, Veluswamy JK, Haardorfer R, Hotz JA, Glanz K. Results from an intervention to improve rural home food and physical activity environments. Prog Community Health Partnersh. 2012;6(3):265-77. https:// doi.org/10.1353/cpr.2012.0042.

32. Kegler MC, Haardorfer R, Alcantara IC, Gazmararian JA, Veluswamy JK, Hodge TL, et al. Impact of improving home environments on energy intake and physical activity: a randomized controlled trial. Am J Public Health. 2016;106(1):143-52. https://doi.org/10.2105/AJPH.2015.302942.

33. Centers for Disease Control and Prevention. Behavioral Risk Factor Surveillance System Survey Questionnaire. Atlanta: U.S. Department of Health and Human Services, CDC; 2015.

34. Thompson FE, Subar AF, Smith AF, Midthune D, Radimer KL, Kahle LL, et al. Fruit and vegetable assessment: performance of 2 new short instruments and a food frequency questionnaire. J Am Diet Assoc. 2002;102(12):1764-72. https://doi.org/10.1016/S0002-8223(02)90379-2.

35. United States Department of Agriculture. 2015-2020 Dietary Guidelines for Americans 2015 Available from: https://health.gov/our-work/food-nutrition/2 015-2020-dietary-guidelines/guidelines/. Accessed March 1, 2020.

36. Thompson FE, Midthune D, Subar AF, Kahle LL, Schatzkin A, Kipnis V. Performance of a short tool to assess dietary intakes of fruits and vegetables, percentage energy from fat and fibre. Public Health Nutr. 2004; 7(8):1097-105. https://doi.org/10.1079/PHN2004642.

37. Glanz K, Sallis JF, Saelens BE, Frank LD. Nutrition environment measures survey in stores (NEMS-S): development and evaluation. Am J Prev Med. 2007;32(4):282-9. https://doi.org/10.1016/j.amepre.2006.12.019.

38. Hedrick VE, Comber DL, Estabrooks PA, Savla J, Davy BM. The beverage intake questionnaire: determining initial validity and reliability. J Am Diet Assoc. 2010;110(8):1227-32. https://doi.org/10.1016/j.jada.2010.05.005.

39. Kristal AR, Shattuck AL, Patterson RE. Differences in fat-related dietary patterns between black, Hispanic and White women: results from the Women's health trial feasibility study in minority populations. Public Health Nutr. 1999;2(3):253-62. https://doi.org/10.1017/S1368980099000348.

40. Fulkerson JA, Story M, Neumark-Sztainer D, Rydell S. Family meals: perceptions of benefits and challenges among parents of 8- to 10-year-old children. J Am Diet Assoc. 2008;108(4):706-9. https://doi.org/10.1016/j.jada.2008.01.005.

41. United States Census Bureau. American Community Survey 20152015 [Available from: https://www2.census.gov/programs-surveys/acs/methodology/ questionnaires/2015/quest15.pdf. Accessed September 10, 2015.

42. Newman SL, Tumin R, Andridge R, Anderson SE. Family meal frequency and association with household food availability in United States multi-person households: National Health and nutrition examination survey 2007-2010. PLoS One. 2015;10(12):e0144330. https://doi.org/10.1371/journal.pone.0144330.

43. Masters MA, Stanek Krogstrand KL, Eskridge KM, Albrecht JA. Race/ethnicity and income in relation to the home food environment in US youth aged 6 to 19 years. J Acad Nutr Diet. 2014;114(10):1533-43. https://doi.org/10.1016/ j.jand.2014.04.023.

44. Gorin AA, Phelan S, Raynor H, Wing RR. Home food and exercise environments of normal-weight and overweight adults. Am J Health Behav. 2011;35(5):618-26. https://doi.org/10.5993/ajhb.35.5.10.

45. Gichunge C, Somerset S, Harris N. Using a household food inventory to assess the availability of traditional vegetables among resettled African refugees. Int J Environ Res Public Health. 2016;13(1):137. https://doi.org/1 0.3390/ijerph13010137.

46. Rolls BJ, Roe LS, Meengs JS. Reductions in portion size and energy density of foods are additive and lead to sustained decreases in energy intake. Am J Clin Nutr. 2006;83(1):11-7. https://doi.org/10.1093/ajcn/83.1.11.

47. Rolls BJ, Roe LS, Meengs JS. Larger portion sizes lead to a sustained increase in energy intake over 2 days. J Am Diet Assoc. 2006;106(4):543-9. https:// doi.org/10.1016/j.jada.2006.01.014

48. An R. Fast-food and full-service restaurant consumption and daily energy and nutrient intakes in US adults. Eur J Clin Nutr. 2016;70(1):97-103. https:// doi.org/10.1038/ejcn.2015.104.

49. Kant AK, Whitley MI, Graubard BI. Away from home meals: associations with biomarkers of chronic disease and dietary intake in American adults, NHANES 2005-2010. Int J Obes. 2015;39(5):820-7. https://doi.org/10.1038/ijo.2014.183.

50. Boutelle KN, Birnbaum AS, Lytle LA, Murray DM, Story M. Associations between perceived family meal environment and parent intake of fruit, vegetables, and fat. J Nutr Educ Behav. 2003;35(1):24-9. https://doi.org/10.1 016/S1499-4046(06)60323-0.

51. Befort C, Kaur H, Nollen N, Sullivan DK, Nazir N, Choi WS, et al. Fruit, vegetable, and fat intake among non-Hispanic black and non-Hispanic white adolescents: associations with home availability and food consumption settings. J Am Diet Assoc. 2006;106(3):367-73. https://doi. org/10.1016/j.jada.2005.12.001.

52. Mamun AA, O'Callaghan MJ, Williams G, Najman JM. Television watching from adolescence to adulthood and its association with BMI, waist circumference, waist-to-hip ratio and obesity: a longitudinal study. Public Health Nutr. 2013;16(1):54-64. https://doi.org/10.1017/\$1368980012002832.

\section{Publisher's Note}

Springer Nature remains neutral with regard to jurisdictional claims in published maps and institutional affiliations. 